\title{
Association between Dyslipidemia and Glycemic control in Children with Type 1 Diabetes Mellitus: A Cross-Sectional Study
}

Leen Jamel Doya ( $\nabla$ dr.leen.doya@gmail.com )

Tishreen University Faculty of Medicine https://orcid.org/0000-0003-0814-5135

Naya Talal Hassan

Tishreen University, Faculty of Medicine

Entessar Nasser

Tishreen University Faculty of Medicine

Muhammad Imad Khayat

Tishreen University Faculty of Medicine

Research article

Keywords: Dyslipidemia, Type 1 diabetes mellitus, glycemic control, hypercholesterolemia, hypertriglyceridemia

Posted Date: July 16th, 2020

DOl: https://doi.org/10.21203/rs.3.rs-41463/v1

License: (9) This work is licensed under a Creative Commons Attribution 4.0 International License. Read Full License 


\section{Abstract}

Background: Type 1 diabetes mellitus (T1DM) and dyslipidemia (DLP) are serious metabolic disorders, and its coexistence has been associated with dangerous outcomes. The purpose of the present study is to investigate dyslipidemia and their relationship with glycosylated hemoglobin ( $\mathrm{HbA1c})$ in Type 1 diabetes mellitus patients.

Methods: In a cross-sectional study design included 118 patients with Type 1 diabetes mellitus aged between 5 and 13 years, who had referred to the outpatient pediatric clinic of endocrinology at Tishreen University Hospital and the Diabetic Center of Latakia, Syria, over 1 year period from October 2018 to November 2019. Anthropometric measurements; serum glycosylated hemoglobin (HbA1C), total cholesterol (TC), high-density lipoprotein cholesterol (HDL-C), low-density lipoprotein cholesterol (LDL), and triglycerides(TG) were measured.

Results: The results showed that there was a significant relationship between dyslipidemia with a higher mean HbA1C $(p=0.0001)$. Also, a significant relationship was found between all lipid profiles expect HDL$\mathrm{C}$ and poor glycemic control. There was no statistical relationship between dyslipidemia and age, gender, body mass index (BMI), or diabetic duration

Conclusion: Glycemic control plays a role as a risk factor for the development of dyslipidemia in children with Type 1 diabetes mellitus.

\section{Introduction}

Type 1 diabetes mellitus (T1DM) is the most common childhood endocrine-metabolic disorder. It results from the marked and progressive inability of the pancreas to secrete insulin because of the autoimmune destruction of beta cells[1]. In recent years, diabetes rates are increasing epidemiologically by $2-5 \%$ per year in Europe, Middle East, and Australia whereas some central and eastern European countries demonstrate an even more rapid increase up to 9\% [2]. In patients with T1DM, chronic complications including nephropathy, neuropathy, retinopathy, peripheral vascular, and cardiovascular diseases (CVD) directly affect the expectancy and long term quality of life [3]. The presence of dyslipidemia increases the frequency and severity of these complications [4].

Diabetic dyslipidemia is defined as low levels of high-density lipoprotein cholesterol (HDL-C) and increased low-density lipoprotein cholesterol (LDL-C), triglycerides (TG), and total cholesterol (TC) [5]. Several studies have evaluated dyslipidemia in patients with type 2 diabetes mellitus, but dyslipidemia in T1DM especially in young children remains largely undiagnosed and undertreated [6-7]. There is no research on dyslipidemia in T1DM children in Syria. Therefore, the recent study aimed to determine lipid profile and its relationship with glycemic control in Syrian T1DM children.

\section{Methods}


A cross-sectional retrospective study included 118 children who had referred to the outpatient pediatric endocrinology clinic at Tishreen University Hospital and the Diabetic Center of Latakia, Syria over 1 year period from October 2018 to November 2019. Patients who had other chronic illnesses, hypothyroidism, celiac disease, familial dyslipidemia, recent diagnosis of diabetes, or taking medications other than insulin were excluded.

Clinical data include age, gender, duration of diabetes since diagnosis, insulin dosage and regimen was obtained from patients and their parents. Physical examination was performed to measure blood pressure $(\mathrm{mmHg})$, weight $(\mathrm{Kg})$, length $(\mathrm{cm})$, and age-specific body mass index (BMl; $\left.\mathrm{Kg} / \mathrm{m}^{2}\right)$. BMI scores were calculated as weight $(\mathrm{kg}) /$ square of length $\left(\mathrm{m}^{2}\right)$ and expressed in Z score, based on the standards assessed by the $\mathrm{CDC}$ growth charts [8].

Laboratory data were obtained after 8-12 hours fasting including glycosylated hemoglobin (HbA1C), TC, TG, LDL-C, HDL-C, anti-tissue transglutaminase (TTG) IgA, thyroid-stimulating hormone (TSH) and cortisol.

Lipid profile was analyzed and classified according to American Heart Association Guidelines 2019 as $\mathrm{TC} \geq 200 \mathrm{mg} / \mathrm{dl}, \mathrm{LDL} \geq 130 \mathrm{mg} / \mathrm{dl}, \mathrm{HDL}-\mathrm{C}<40 \mathrm{mg} / \mathrm{dl}, \mathrm{TG} \geq 100 \mathrm{mg} / \mathrm{dL}$ for children younger than 10 years and $\geq 130 \mathrm{mg} / \mathrm{dL}$ for older than 10 years. Dyslipidemia was defined by the presence of one or more abnormal serum lipid concentrations [9].

$\mathrm{HbA} 1 \mathrm{C}$ was determined by using an I-Chroma $\mathrm{HbA} 1 \mathrm{C}$ kit based on the immunofluorescence assay method. the normal range was $4.5-6.5 \%$.

Diabetic children classified as optimal glycemic control (OGC) and poor glycemic control (PGC) according to the recommendation from American Diabetes Association (ADA) that contains $\mathrm{HbA1C}$ values in T1DM children according to age; up to 6 years: $7.5-8.5 \%, 6-12$ years: $<8 \%, 13-19$ years: $<7.5 \%[10]$.

All data were analyzed using the Statistical Package for Social Sciences (SPSS Version 20). Data were presented in simple measures of frequency, percentage, mean, standard deviation. The significance of the difference between different means (quantitative data) was tested using Student's t-test for the difference between two independent means, while different percentages (qualitative data) were tested using Pearson's Chi-square test. Results were considered statistically significant with a $p$-value $<5 \%$.

This study was reviewed and approved by the ethical Committee of Tishreen University Hospital, all participants provide informed consent and /or assent.

\section{Results}

The study included 118 children with T1DM, 60(50.8\%) were female and 58(49.20\%) were male with a mean age of $10 \pm 2.3$ years ( $5-13$ years). The mean duration of T1DM since diagnosis was $(3.4 \pm 2.3$ years; range from 1 year to 10.2 years), and the mean $\mathrm{HbA} 1 \mathrm{C}$ was ( $8.4 \pm 1.9 \%$; range $4.5 \%-14.4 \%$ ). All 
patients received two doses of insulin (a mixture of intermediate and short action) per day. The mean insulin dose was $(0.69 \pm 0.1 \mathrm{U} / \mathrm{Kg} /$ day; range $0.5-1.2 \mathrm{U} / \mathrm{Kg} /$ day $)$.

The frequency of dyslipidemia was $48.3 \%$. overall, 57 patients had dyslipidemia which included: 27(22.9\%) patients with a low level of HDL-C, 25(21.2\%) patients with hypertriglyceridemia, 22(18.6\%) patients with hypercholesterolemia, 19(16.1\%) patients with a high level of LDL-C (Fig. 1 ).

Comparison between dyslipidemic and normolipidemic groups, There were no significant differences between the two groups regarding age, sex, $\mathrm{BMI}$, duration of diabetes. $\mathrm{HbA} 1 \mathrm{c}$ was significantly higher in the dyslipidemic group $(P=0.0001)$ (Table 1$)$.

To evaluate the association between lipid values and glycemic control, we categorized patients into two groups according to the values of HbA1C recommended by ADA[10]. There was $46.7 \%(55)$ of patients with OGC, and 53.3\%(63) with PGC. when comparing OGC group with PGC group, Hypercholesterolemia, hypertriglyceridemia, and high LDL-C were statistically significant. There was no statistically significant difference in low HDL-C between OGC group and PGC group. (Table 2).

\section{Discussion}

There is no detailed information about the prevalence of T1DM and its association with dyslipidemia in Syria, but according to evidence predicate globally increasing of T1DM and its complications [11]. The current study supports the importance of clinical and research interest in blood samples and T1DM children. $53.3 \%$ of patients were PGC, probably because most of them were from low socioeconomic levels and provided treatment at a free public health center.

In the current study, $48.3 \%$ of T1DM patients had dyslipidemia. Dyslipidemia frequency in diabetic children varies between $3.8 \%$ and $74.8 \%$ in different studies [12-13]. In a study from Iran, the ratio of dyslipidemia among 274 T1DM patients was $74.8 \%$ and it was shown that the majority dyslipidemia developed was hypercholesterolemia, and hypertriglyceridemia was less frequently[13]. In a study from Turkey, the rate of dyslipidemia in patients with T1DM was found to be $26.2 \%$ with a high prevalence of hypercholesterolemia and hypertriglyceridemia[14]. A possible explanation of variation reports includes multiple genetic factors in different ethnic groups, the diet and physical activity of the general population, and different laboratory methods [15-16].

The current study showed that there was a relationship between dyslipidemia and glycemic control. This result is in concordance, Bulut et al found that glycemic control in T1DM had a direct effect on DLP [14]. This can be explained by insulin deficiency that leads to increase in the release of lipoprotein lipase from adipose tissue, besides, increased very-low-density lipoprotein (VLDL) and free fatty acid [17]. It was observed that abnormal TG, TC, and LDL-C were higher in PGC patients compared to OGC patients participants with a significant association $(p=0.003, p=0.0001$, and $p=0.007$, respectively). whereas abnormal HDL-C was found in PCG patients more than OGC patients but with no significant association 
$(p=0.1)$. The same finding in the study of Bangladesh [18], which can be explained that HDL-C disorder is affected by many factors include genetics, dietary habits, lifestyle, and physical activity[19].

Zabeen et al showed that there is a significant relationship between levels of $\mathrm{HbA} 1 \mathrm{C}$ in patients and abnormal HDL-C [20], this modification has been attributed to an increase cholesterol ester transfer between lipoproteins which increases the transfer of TG to HDL-C, resulting in an increase in HDL-C content from TG, thus increasing its susceptibility to breakage [21]. Mostofizadeh et al study showed that LDL-C was higher in PGC patients and this corresponds to the result of the current study [13]. This can be explained by insulin deficiency in PGC patients, which reduces the number of available LDL-C receptors and thus increases their concentration [22].

Poor information and Awareness of nutrition content of local food and calories spent were limitations of data collected for this study. Repeated measurement of fasting lipids was not made over time in individual subjects that may be also a limitation.

\section{Conclusion}

We conclude that Glycemic control is a modifiable red flag marker that causes dyslipidemia among children with T1DM. More studies with larger samples and the possibility of following up with patients after improving glycemic control are recommended.

\section{Declarations}

\section{Ethics approval and consent to participate::}

All parents whose children were studied gave informed consent for the sharing of this research. Ethical clearance for this study was obtained from the Ethical Committee of Tishreen University Hospital.

Consent for publication: All parents whose children were studied gave informed consent for publication the research.

\section{Availability of data and materials:}

We can't share patient data due to our hospital 's privacy policy, which concerns with maintaining patient confidentiality and refuses to publish or share data. Also, the informed consent signed by parents to participate in the study prevents the sharing of information with the unknown researchers.

Competing interests: Not applicable.

Funding : Not applicable.

\section{Author Contributions:}


Both authors developed and carried out sample collection. Literature review was done by Dr. Leen Doya, and both authors did data analysis and read through the final data.

\section{Acknowledgments:}

We wish to thank the medical officer, doctors in the pediatric department, and laboratory assistants in Tishreen University Hospital laboratory who worked with us in reviewing the patients and doing the laboratory analysis. We want to thank Miss Elissar Hejazia, Dr Lava Mohammad for technical help. We appreciate the great efforts of Prof. Dr. Ahmad Chreitah. We want to thank the parents, the patients for their consent to participate in this study.

\section{Abbreviations}

T1DM :Type 1 Diabetes Mellitus.

HbA1c: Glycated Hemoglobin.

BMI : Body Mass Index

HDL-C: High-Density Lipoprotein Cholesterol.

LDL-C : Low-Density Lipoprotein Cholesterol.

TG : Triglycerides.

TC : Total Cholesterol.

DLP : Dyslipidemia.

PGC : Poor Glycemic Control.

OGC : Optimal Glycemic Control.

VLDL-C : Very-Low-Density Lipoprotein Cholesterol.

CVD: Cardiovascular Disease.

\section{References}

1. McCulloch DK, Palmer JP. The appropriate use of B-cell function testing in the preclinical period of type 1 diabetes. Diabetic Medicine : a Journal of the British Diabetic Association 1991;8(9):800-804. Doi:10.1111/j.1464-5491.1991.tb02116.x.

2. Imkampe AK, Gulliford MC. Trends in Type 1 diabetes incidence in the UK in 0- to 14-year-olds and in 15- to 34-year-olds, 1991-2008. Diabet Med 2011; 28(7):811-4. doi:10.1111/j.1464-5491.2011.03288.x 3. Atkinson, Mark, Eisenbarth, George S, Michels, Aaron W. Type 1diabetes. The Lancet 2014;6736:69-82. 
Doi:10.1515/jpem-2016-0111

4. Simsek DG, Aycan Z, Özen S, Cetinkaya S, Kara C, Abalı S, et al. Diabetes care, glycemic control, complications, and concomitant autoimmune diseases in children with type 1 diabetes in Turkey: a multicenter study. J Clin Res Pediatr Endocrinol. 2013; 5(1): 20-6. Doi: 10.4274/Jcrpe.893.

5. Schwab KO, Doerfer J, Marg W, Schober E, Holl RW, DPV Science Initiative and the Competence Network Diabetes mellitus. Characterization of 33488 Children and Adolescents with Type 1 Diabetes Based on the Gender-Specific Increase of Cardiovascular Risk Factors. Pediatric Diabetes 2010; 11(5): 357-363.doi:10.1111/j.1399-5448.2010.00665.x

6. Hamad A, Qureshi HJ . Dyslipidaemia in recently diagnosed young subjects of type 1 diabetes mellitus with normal/favourable BMI: a risk factor of macrovascular disease. Biomedica 2008;24: 130-3.

7. Wadwa RP, Kinney GL, Maahs DM, Snell-Bergeon J, Hokanson JE, et al. Awareness and treatment of dyslipidemia in young adults with type 1 diabetes. Diabetes Care 2005;28: 1051-1056.

8. Kelly, A.S., Barlow, S.E., Rao, G., Inge, T.H., Hayman, L.L., Steinberger, et al. Severe Obesity in Children and Adolescents: Identification, Associated Health Risks, and Treatment Approaches. A Scientific

Statement From The American Heart Association. Circulation. 2013;128(15): 1689-1712.

Doi:10.1161/CIR.0b013e3182a5cfb3

9. Grundy, S.M., Stone, N.J., Bailey, A.L., Beam, C., Birtcher, K.K., Blumenthal, R.S., et al. (2019) AHA/ ACC/ AACVPR/ AAPA/ ABC/ ACPM/ ADA/AGS/APhA/ASPC/NLA/PCNA guideline on the management of blood cholesterol: a report of the American College of Cardiology/American Heart Association Task Force on Clinical Practice Guidelines. J Am Coll Cardiol. 2019 ;73(24):3168-3209.

Doi:10.1161/CIR.0000000000000625

10. Chiang JL, Kirkman MS, Laffel LM, Peters AL. (2014) Type 1 diabetes through the life span: a position statement of the American Diabetes Association. Diabetes Care 2014;37(7):2034-2054.

Doi:10.2337/dc14-1140

11. You WP, Henneberg M. Type 1 diabetes prevalence increasing globally and regionally: the role of natural selection and life expectancy at birth. BMJ Open Diabetes Res Care 2016; 4: e000161. Doi:10.1136/bmjdrc-2015-000161

12. Redondo MJ, Foster NC, Libman IM, Mehta SN, Hathway JM, et al . Prevalence of cardiovascular risk factors in youth with type 1 diabetes and elevated body mass index. Acta Diabetologica.2015; 53(2): 271277. Doi:10.1007/s00592-015-0785-1

13. Mostofizadeh N, Hashemipour M, Roostazadeh M, Hashemi-Dehkordi E, Shahsanai A, Reisi M,et al. The impact of poor glycemic control on lipid profile variables in children with type 1 diabetes mellitus.Journal of Education and Health Promotion 2019; 2019(8). Doi:10.4103/jehp.jehp_194_17 14. Bulut T, Demirel F, Metin A. The prevalence of dyslipidemia and associated factors in children and adolescents with type 1 diabetes. Journal of Pediatric Endocrinology and Metabolism.2017; 30(2): 181187.

Doi:10.1515/jpem-2016-0111

15. El Bakry MM, Mansour Al, Ahmed ME, Sptan HE. Dyslipidemia in Egyptian children and adolescents with type 1 diabetes mellitus. Benha Medical Journal 2017, 34:104-107. Doi:10.4103/bmfj.bmfj_15_17 16. Ali SM. Significance of Lipid Profiles and Glycemic Control in Children with Diabetes Mellitus in 
Baqubah City, Tikrit Medical Journal 2017;22(1):16-24

17. Wu L, Parhofer KG. Diabetic dyslipidemia. Metabolism.2014;63(12) : 1469-79.

Doi:10.1016/j.metabol.2014.08.010

18. Parveen M, Muttalib MA, Huq ST, Nazneen N, Kabir MA, Hossain MS.Evaluation of lipid profile among children and adolescents with type 1 diabetes mellitus in Bangladesh. Mediscope. 2018; 5(1):15-21 doi:10.3329/mediscope.v5i1.36721

19. Lopes-Virella MF, Wohltmann HJ, Mayfield RK, Loadholt CB, Colwell JA. Effect of metabolic control on lipid ,lipoprotein and apolipoprotein levels in 55 insulin dependent diabetic patients Diabetes.

1984;32(1):20-25. Doi:10.2337/diab.32.1.20

20. Zabeen B, Balsa AM, Islam N, Parveen M, Nahar J, Azad K. Lipid Profile in Relation to Glycemic Control in Type 1 Diabetes Children and Adolescents in Bangladesh.Indian J Endocr Metab. 2018;22(1):89-92. Doi:10.4103/ijem.IJEM_217_17

21. Verges, B. Lipid disorders in type 1 diabetes. Diabetes \& metabolism. 2009;35(5), 353-360.

Doi:10.1016/j.diabet.2009.04.004

22. Hirano T. Pathophysiology of Diabetic Dyslipidemia. J Atheroscler Thromb, 2018; 2018:RV17023.Doi: $10.5551 /$ jat.RV17023

\section{Tables}

Table (1)

Characterizes of patients with and without dyslipidemia

\begin{tabular}{|c|c|c|c|}
\hline Variables & Dyslipidemia & Normolipidemia & $\bar{P}$ \\
\hline Age - years(SD) & $10.3(2.5)$ & $9.8(2.3)$ & 0.2 \\
\hline Gender (female),n(\%) & $31(54.4)$ & $29(47.5)$ & 0.4 \\
\hline \multicolumn{4}{|l|}{ BMI } \\
\hline Underweight, $\mathrm{n}(\%)$ & $19(33.3)$ & $13(21.3)$ & \multirow[t]{4}{*}{0.2} \\
\hline Normal weight , n(\%) & $36(63.2)$ & $\overline{44(72.1)}$ & \\
\hline Overweight , $\mathrm{n}(\%)$ & $2(3.5)$ & $2(3.3)$ & \\
\hline Increase weight,n(\%) & $0(0)$ & $2(3.3)$ & \\
\hline Duration Disease- years(SD) & $3.3(2.4)$ & $3.4(2.2)$ & 0.7 \\
\hline HBA1C - \%(SD) & $9.2(2.03)$ & $7.6(1.5)$ & 0.0001 \\
\hline PGC, n(\%) & $43(68.3)$ & $20(31.7)$ & \multirow[t]{2}{*}{0.0001} \\
\hline OGC, $\mathrm{n}(\%$ & $14(25.5)$ & $41(74.5)$ & \\
\hline
\end{tabular}

HBA1C: glycosylated hemoglobin, BMI: body mass index, OCG: optimal glycemic control, PCG: poor glycemic control

Table (2)

Comparison of different types of dyslipidemia with PGC and OGC 


\begin{tabular}{|r|c|c|l|}
\hline Dyslipidemia & OGC & PGC & \multicolumn{1}{|c|}{ P } \\
\hline TC , n(\%) & $1(1.8)$ & $21(33.3)$ & 0.0001 \\
\hline TG , n(\%) & $5(9.1)$ & $20(31.7)$ & 0.003 \\
\hline LDL-C , n(\%) & $3(5.5)$ & $16(25.4)$ & 0.007 \\
\hline HDL-C , n(\%) & $9(16.4)$ & $18(28.6)$ & 0.1 \\
\hline
\end{tabular}

OCG: optimal glycemic control, PCG: poor glycemic control, TC: total cholesterol, TG: triglycerides, LDLC: low-density lipoprotein cholesterol, HDL-C: high-density lipoprotein cholesterol

\section{Figures}

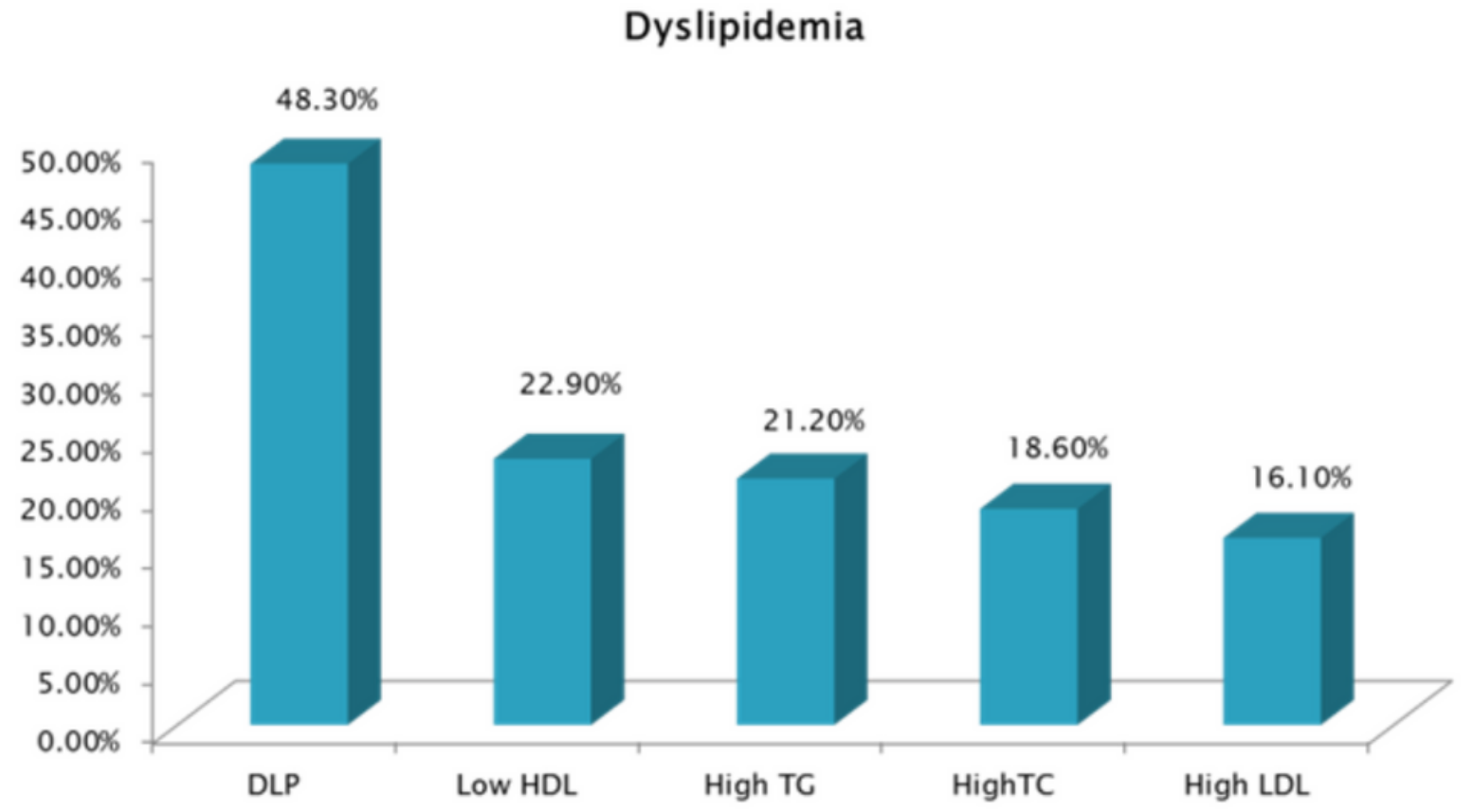

Figure 1

Different types of dyslipidemia 